\title{
Proceeding
}

Supplementary Issue: Spring Conferences of Sports Science. Costa Blanca Sports Science Events, 19-20 June 2020. Alicante, Spain.

\section{The formative value of soccer rules}

\author{
GAETANO RAIOLA ${ }^{1} \triangleleft$, GIOVANNI ESPOSITO ${ }^{1}$, FRANCESCO SGRÒ2 \\ ${ }^{1}$ Department of Human, Philosophical and Education Sciences, University of Salerno, Italy \\ 2University Kore of Enna, Italy
}

\begin{abstract}
The rules of the game of football and the technical and tactical methods applicable to them are indispensable for playing sports in a competitive way. The correct competition was born from the automatic mechanism of the sanction following the violation of a game rule, which is also favoured by the relational dynamics of the individual members of the group who claim the application of the rule to continue playing. The competition can also be self-regulated by the two groups that compete for the victory without even the decisive action of the referee, as always happens in training activities. This phenomenon is found only in those contexts where the rule is necessary and sufficient on its own to guarantee the orderly development of the activities. The aim of the study is to identify significant elements of the game rules and related technical and tactical behaviours in football and to identify an inventory of significant behaviours. The method is documentary archival research for the analysis of the rules of individual team sports, a subsequent comparative method between grids of indicators, descriptors and weights that classify rule, technique and tactics. The expected results will focus on the appropriate presence of significant elements and commonality or discordance. The data are useful for measuring the amount of significant behaviours for qualitative processing of the value of each of them compared to other current behaviours of quantitative performance and for establishing connections. Subsequently, requests for self-perception can be administered to practitioners (athletes and students) on the specific connections between the need for the rule and its application in order to play sportily at the highest levels with gratification and satisfaction. The results are useful for any reflection and attention to the reproducibility of the mechanism studied for other social activities through an educational and training action. Keywords: Football; Rules; Technique and tactics.

\section{Cite this article as:}

Raiola, G., Esposito, G., \& Sgrò, F. (2020). The formative value of soccer rules. Journal of Human Sport and Exercise, 15(3proc), S656-S663. doi:https://doi.org/10.14198//hse.2020.15.Proc3.18
\end{abstract}

Corresponding author. Department of Human, Philosophical and Education Sciences, University of Salerno, Italy. http://orcid.org/0000-0002-7659-1674

E-mail: raiolagaetano@libero.it

Supplementary Issue: Spring Conferences of Sports Science. Costa Blanca Sports Science Events, 19-20 June 2020. Alicante, Spain.

JOURNAL OF HUMAN SPORT \& EXERCISE ISSN 1988-5202

(c) Faculty of Education. University of Alicante

doi:10.14198/jhse.2020.15.Proc3.18 


\section{INTRODUCTION}

Football is one of the most popular and long-lasting sports in human history. This sport takes place on a rectangular playing field with two doors at the end, with the playing tool being a ball. The goal is to regularly place this ball inside the opponent's goal. To play a football game of honesty and fun there is a need for rules, which are applied by the referee on the field (Patrizia et al., 2019). Starting from the rules, it is possible to develop on an individual level the technique that is made up of the various foundations of football (Ceruso et al., 2019). The latter are divided into defensive fundamentals, so when the team is in the non-possession phase and offensive fundamentals when the team is in the possession phase (Sgrò et al, 2016). When a footballer has developed the individual technique, performing a specific training from a young age, he can approach any collective tactics of a team. A player must therefore know the rules, respect for the referee, his teammates and his opponents. Before going into details, it is useful to specify that there is a distinction between the programming of "esordienti", "giovanissimi", "allievi and juniores". The intervention, in the first case, will be connected to individual care, basic technique and individual tactics with some suggestions for collective organization (Ceruso et al., 2019). So, some mentions of systems, modules and collective tactics are indispensable in proportion to the age of the children and their ability to understand certain notions. For the other two age groups, a different approach is needed. The principles of collective tactics must be there, but without exasperation (Esposito et al., 2019). A youth manager's mission is to improve the single player game. Because it is individual improvement that makes a player in a collective context. It is clear that all children have the right to improve, from the first to the last, from the strongest to the one with some difficulty (Altavilla et al., 2017). Trying to manage the game with young people is one of the main goals of each coach, indeed the first goal. To do this, it is necessary to work on both technical and tactical aspects and those relating to the sphere of personality. It is not easy; you need time and determination in training and not all races can be controlled. Through training and through some mistakes, players must overcome the fear of handling the ball: you have to start from the youngest, to set a precise and conscious path (Izzo et al., 2019). You have to pass the message that the result is obtained through the manoeuvre and the performance. The objectives to be pursued must be clear for both the coach and the team. The main ones are:

- Technical-tactical: improves the fundamental in which you miss or weak foot;

- Physical: you can start from the tests, show some gaps and propose exercises to fill them;

- Mental: determination, control of aggression, courage, tension.

Never forget the fun component in all of this. The pleasure of playing football, being in a group, growing up with friends are some sources that push young people to come on the pitch. Every coach must keep this in mind (Rago et al., 2017). Everyone must act with the utmost professionalism, respecting the rules and with education, always, but the playful component must never be missing. Free play must be present in training. A free game at a good pace, with internal challenges between teams, challenging and fun. Not all of them are champions, the champion was born with special qualities, it is something innate, which cannot be achieved through specific work. Through the latter, it is possible to improve, but some solutions are specific to the genetic heritage (Russo et al., 2019). But it must be considered that there are different talents, characterized by very different abilities. There is technical talent (with above average sensitivity), tactical talent (excellent readings of the game, ability to anticipate and ability to make choices), physical talent (typical of those elements with important athletic skills in terms of ability, speed, explosiveness and reactivity). Lastly there is the head. There are those who are mentally capable of making a difference, they are determined, they do not give up because they have character and personality (Raiola, 2014). We must allow him to express himself, test his skills to overcome problems, do not rely on him and stop (Raiola, 2015). Interpersonal relationships count, for example, some words of encouragement or consolation. Exercises, training programs, corrective actions, tactics and techniques, physical preparation, are all important aspects 
for a coach. Fundamental because they aim to improve their players, all this is used according to the working method that each technician has built during his career. The working method represents the way in which training means, planned programs and purely football aspects are used. It means not acting casually but meditating on all the behaviours you have on the field (Ceruso et al., 2019). But that is not enough: you need a method even off the pitch. In fact, it is crucial and functional for what you intend to propose on the green rectangle. It's the base.

\section{Aim of the study}

The aim of this study is to identify the significant elements of the game rules and the related technical tactical behaviours to be adopted in the various game situations in the football team. All this allows us to define an inventory of significant behaviours to be subjected to qualitative processing. The value of each of them will also be measured with respect to the other current qualitative performance behaviours by establishing connections.

\section{METHODS AND MATERIALS}

On the one hand, the method involves archival research with a documentary approach for analysing the rules that characterize the team sport in question; on the other hand, it provides a comparison between grids of indicators, descriptors and weights (i.e. the degree of connection between indicator and descriptor) which allows to classify the rule, technique and tactics. In the first phase, the analysis of the rules of football was conducted, with which we tried to establish a connection with the technical and tactical aspects necessary to achieve the set of specific goals. The identified rule represented the indicator, while the technical and tactical proposals represented the first and second descriptors respectively. The degree of connection between the indicator and the descriptor was then assessed, assigning a qualitative value between three choices: close, medium or low connection. In the second phase of the research, the relationship of each of the previously identified elements with the performance data was identified in a descriptive way. In practice, the degree of physical commitment, the degree of strength and speed for each of the indicators-descriptors identified were assessed, also assigning in this case a qualitative value among the possible alternatives: maximum, average and minimum commitment. The data are therefore useful for measuring the quantity of significant behaviours for qualitatively processing the value of each of them compared to the other current behaviours of quantitative performances and for establishing connections. The results can be useful for possible reflections and focus on the reproducibility of the mechanism studied for other social activities through an educational and training action.

\section{RESULTS}

Table 1. Summary of data collected.

\begin{tabular}{|c|c|c|c|c|c|c|}
\hline Indicator & 1st descriptor & 2nd descriptor & $\begin{array}{l}\text { Indicator- } \\
\text { descriptor } \\
\text { connection }\end{array}$ & \multicolumn{3}{|c|}{$\begin{array}{l}\text { Connection with the performance } \\
\text { data }\end{array}$} \\
\hline Rule & Technical proposal & Tactical proposal & Weight & $\begin{array}{l}\text { Degree of } \\
\text { physical } \\
\text { commitment }\end{array}$ & $\begin{array}{l}\text { Degree of } \\
\text { strength }\end{array}$ & $\begin{array}{l}\text { Degree } \\
\text { of speed }\end{array}$ \\
\hline $\begin{array}{l}\text { The game is played } \\
\text { on a rectangular } \\
\text { field } 90 \text { to } 120 \\
\text { meters long and } 45 \\
\text { to } 90 \text { meters wide. } \\
\text { The doors are }\end{array}$ & $\begin{array}{l}\text { Offensive phase: } \\
\text { Transmission, } \\
\text { reception and free } \\
\text { conduct of the ball } \\
\text { (which can be } \\
\text { transformed into }\end{array}$ & $\begin{array}{l}\text { Offensive phase: } \\
\text { depth, amplitude, } \\
\text { unpredictability. } \\
\text { Defensive phase: } \\
\text { Defensive } \\
\text { concentration, }\end{array}$ & Strict & Medium & Minimum & Maximum \\
\hline
\end{tabular}




\begin{tabular}{|c|c|c|c|c|c|c|}
\hline $\begin{array}{l}\text { arranged in the } \\
\text { centre of the two } \\
\text { lower sides. }\end{array}$ & $\begin{array}{l}\text { dribbling), shot on } \\
\text { goal and header. } \\
\text { Defensive phase: } \\
\text { Defence of a space, } \\
\text { interception, contrast } \\
\text { and anticipation. } \\
\end{array}$ & $\begin{array}{l}\text { space limitation } \\
\text { control. }\end{array}$ & & & & \\
\hline $\begin{array}{l}\text { The number of } \\
\text { players equals a } \\
\text { total of } 22 \text { people, } \\
11 \text { players per team } \\
\text { consisting of } 10 \\
\text { moving players plus } \\
\text { a goalkeeper. }\end{array}$ & $\begin{array}{l}\text { Offensive phase: } \\
\text { Placement } \\
\text { Defensive phase: } \\
\text { Defend a space }\end{array}$ & $\begin{array}{l}\text { Defensive and } \\
\text { offensive } \\
\text { staggering }\end{array}$ & Strict & Medium & Medium & Medium \\
\hline $\begin{array}{l}\text { The signature of a } \\
\text { goal (when it is } \\
\text { regular and can be } \\
\text { validated). }\end{array}$ & $\begin{array}{l}\text { Shake off, reception, } \\
\text { shot on goal and } \\
\text { header. }\end{array}$ & $\begin{array}{l}\text { Mobility and } \\
\text { unpredictability }\end{array}$ & Strict & Maximum & Maximum & Maximum \\
\hline $\begin{array}{l}\text { The offside is } \\
\text { applied when one } \\
\text { or more offenders } \\
\text { who are about to } \\
\text { receive the ball are } \\
\text { behind the last } \\
\text { defender or behind } \\
\text { the goalkeeper at } \\
\text { the start of the } \\
\text { transmission of the } \\
\text { ball of his } \\
\text { teammate. }\end{array}$ & Defend a space & $\begin{array}{l}\text { Defensive } \\
\text { concentration and } \\
\text { staggering }\end{array}$ & Strict & Medium & Minimum & Maximum \\
\hline $\begin{array}{l}\text { The free kick is } \\
\text { awarded following } \\
\text { an incorrect play } \\
\text { against the } \\
\text { opponent. }\end{array}$ & $\begin{array}{l}\text { Offensive phase: } \\
\text { Transmission and } \\
\text { shot on goal } \\
\text { Defensive phase: } \\
\text { defence of a space, } \\
\text { marking and } \\
\text { interception. }\end{array}$ & $\begin{array}{l}\text { Offensive phase: } \\
\text { Mobility and } \\
\text { unpredictability } \\
\text { Defensive phase: } \\
\text { defensive } \\
\text { concentration and } \\
\text { control and } \\
\text { limitation of } \\
\text { spaces. }\end{array}$ & Strict & Medium & Medium & Maximum \\
\hline $\begin{array}{l}\text { The penalty is a } \\
\text { penalty that is } \\
\text { awarded after a foul } \\
\text { committed in the } \\
\text { penalty area by the } \\
\text { defending team to } \\
\text { the team that } \\
\text { committed the foul. }\end{array}$ & $\begin{array}{l}\text { Offensive phase: } \\
\text { Shot } \\
\text { Defensive phase: } \\
\text { Goalkeeper } \\
\text { technique, defend a } \\
\text { space on the } \\
\text { goalkeeper's } \\
\text { rejection. }\end{array}$ & $\begin{array}{l}\text { Offensive phase: } \\
\text { unpredictability } \\
\text { and mobility } \\
\text { Defensive phase: } \\
\text { Defensive } \\
\text { concentration and } \\
\text { control and } \\
\text { limitation of } \\
\text { spaces. }\end{array}$ & Medium & Maximum & Medium & Maximum \\
\hline $\begin{array}{l}\text { Throw-in after the } \\
\text { ball has crossed } \\
\text { one of the court's } \\
\text { two lateral lines. }\end{array}$ & Throw-in & $\begin{array}{l}\text { Offensive phase: } \\
\text { mobility } \\
\text { Defensive phase: } \\
\text { Defensive } \\
\text { concentration and } \\
\text { control and } \\
\text { limitation of } \\
\text { spaces. }\end{array}$ & Strict & Medium & Maximum & Maximum \\
\hline
\end{tabular}




\begin{tabular}{|l|l|l|l|l|l|l|}
\hline $\begin{array}{l}\text { Referral from the } \\
\text { bottom is awarded } \\
\text { when the team that } \\
\text { committed the foul } \\
\text { causes the ball to } \\
\text { cross the line at the } \\
\text { bottom of the } \\
\text { opponent's court. }\end{array}$ & $\begin{array}{l}\text { Kicks: short or long } \\
\text { transmission. }\end{array}$ & $\begin{array}{l}\text { Offensive phase: } \\
\text { width, depth, loss } \\
\text { and mobility. } \\
\text { Defensive phase: } \\
\text { strattering }\end{array}$ & Strict & Maximum & Maximum & Maximum \\
\hline $\begin{array}{l}\text { Corner kick is } \\
\text { awarded when the } \\
\text { defending team } \\
\text { crosses its own } \\
\text { bottom line. }\end{array}$ & $\begin{array}{l}\text { Offensive phase: } \\
\text { kicks (transmission or } \\
\text { shooting), marking } \\
\text { and reception. } \\
\text { Defensive phase: } \\
\text { Marking, defence of a } \\
\text { space and } \\
\text { interception. }\end{array}$ & $\begin{array}{l}\text { Offensive phase: } \\
\text { mobility, } \\
\text { unpredictability. } \\
\text { Defensive phase: } \\
\text { defensive } \\
\text { concentration, } \\
\text { control and } \\
\text { limitation of } \\
\text { spaces. }\end{array}$ & Strict & Medium & Maximum & Maximum \\
\hline $\begin{array}{l}\text { The ball is the main } \\
\text { tool for performing } \\
\text { the sport of football. }\end{array}$ & $\begin{array}{l}\text { Offensive phase: } \\
\text { transmission, } \\
\text { reception, shot on } \\
\text { goal, header, } \\
\text { conduction of the ball } \\
\text { and dribbling. } \\
\text { Defensive phase: } \\
\text { Heading, interception } \\
\text { and contrast. }\end{array}$ & $\begin{array}{l}\text { Offensive phase: } \\
\text { unpredictability } \\
\text { Defensive phase: } \\
\text { temporization }\end{array}$ & Strict & Medium & Medium & Medium \\
& & & & & & \\
\hline
\end{tabular}

The various rules have been included in this table, with a correlation attached with technique and tactics. In addition, varying degrees of use of physical effort, strength and speed have been added.

\section{DISCUSSION}

The basic rule concerns the size of the playing field. By regulation, in fact, the game must be performed on a rectangular field 90-120 meters long and 45-90 meters wide. The doors are arranged in the centre of the two lower sides. Within this space, an individual player can guide the ball, transmit and receive it, perform a header and kick in the goal all aspects of a purely technical nature that must be tried and trained through specific sessions. These are the main foundations used in this sport, the so-called basic technical foundations (Altavilla et al., 2015). Obviously in front of an offender there will be a defender who will have to master the defensive technique which includes: the defence of a space, the contrast, the interception, and the advance. The indicator and the 2 descriptors are closely linked, since the use of the most effective individual techniques and tactics is preferred based on the tone (Esposito et al., 2019). The degree of physical effort is considered medium because the game situations are variable, the degree of minimum strength and finally that of maximum speed since if you are faster than your opponent you can put him in difficulty.

The second rule concerns the number of players on the field which equates to a total of 22 people. Eleven players per team consisting of 10 moving players plus one goalkeeper. To better occupy the field, it is necessary to know the principles of the applied technique. The players in possession must be able to position themselves preferably in the empty spaces to open the opposing defence. At the same time, defenders must defend a space. The teams apply both defensively and offensively the astonishment which is defined as the distribution of players on the pitch and the subsequent creation of lines made up of multiple players. The correlation between indicator and descriptor is close because, based on the number of players dictated by 
the rule, what is indicated in the first and second descriptors takes place. All three grades mentioned in the table are defined as medium, because in the field, thanks to the performance, we find neither low nor maximum relationships.

Another interesting starting point concerns the signing of a network (when it is regular and can be validated). Better known as the famous "goal", that is the positioning of the ball on goal. A footballer can perform a goal through a shot on goal, a header but also casually through a detour, or involuntarily execute another fundamental such as a cross or a cross. Also, to score goals, a player must cancel to receive the ball. From a technical point of view, it would be enough to dedicate at least one day a week a session entirely dedicated to shots on goal both in an upright and dynamic position. At a collective tactical level, a lot of work must be done in terms of mobility, breadth and unpredictability (Gaetano, 2016). Individual and collective tactics are closely related to the rule and also imply a maximum use of the three degrees mentioned above. Closely related to the goal of a goal, the free kick and the penalty shot are taken. The punishment is awarded following an incorrect play against the opponent. This rule allows the team that committed the foul to be able to score a goal by kicking the goal directly or the batsman can assist a teammate. On a tactical level, unpredictability in the offensive phase is necessary. The hitting player must consider several aspects including the positioning of the goalkeeper and the barrier, the distance from the goal and the anatomical surface that should be used depending on the situation. On the contrary, in the defensive phase, defensive concentration is necessary, trying to limit the spaces. The correlation between indicator and descriptor is tight, moreover the degree of physical effort and strength is medium, that of speed is maximum. The free kick is the penalty that is awarded after a foul committed in the penalty area by the defending team to the team that committed the foul. Individually the attacker must use the shot on goal to score, the defenders need the goalkeeper and his technique and therefore a defence of the spaces in case of a post or a crossbar or the goalkeeper himself (Sgrò et al., 2017). The correlation between indicator and descriptor is tight, moreover the physical effort is maximum, that of strength is average and finally that of speed is maximum. Other rules identified concern situations that make this sport specific: the offside rule, the kick-off and the corner kick.

Unlike the 5-a-side cheese in 11-a-side football, an offside is foreseen, which is applied when one or more offenders who are about to receive the ball, are behind the last defender or behind the goalkeeper at the beginning of the transmission of the ball of the his partner team (Esposito et al., 2019). It is a rule that regards the guilty team, but to allow the application a great development of individual tactics that includes the defence of a space and at a collective level includes defensive and disconcerting concentration is necessary. The connection between indicator and descriptor is close. The degree of physical effort is described as medium, the degree of minimum force and finally that of maximum speed. The throw-in takes place after the ball has passed one of the two lateral lines of the court. It is performed with the assigned player's hands. Besides being a rule, it is one of the foundations that a player must know, because in case of a wrong shot, the joke is granted to the opposing team. Mobility and unpredictability are used collectively in the offensive phase, while concentration, control and limitation of spaces are defensive (Giordano et al., 2019). The correlation between indicator and descriptor is tight, moreover the degree of physical effort is medium, unlike that of force and speed which is maximum. Return from the bottom is allowed when the team that committed the foul causes the ball to cross the line on the bottom of the opponent's court. It can be performed by both the goalkeeper and a moving player. On an individual level to perform this gesture, we need the transmission, long or short. Instead, as far as the collective is concerned, the width, the depth, the offset and the mobility are used for the ball owners. Instead defenders use defensive concentration, control and limitation of spaces. The correlation between indicator and descriptor is close. Both the degree of physical commitment and that of strength and speed are maximum. 
The corner is awarded when the defending team crosses its own bottom line. Preferably, the batter tries to provide assistance to a teammate, but it has happened several times that he has directly sought the goal by signing the so-called Olympic goal. Therefore, whoever executes it uses the long or short transmission that is or the shot on goal, while who must receive uses the sign, the reception and possibly the shot on goal. As for the defender, he uses marking, defending a space and interception (Gaetano et al., 2017). On a collective level, for those who offend there is mobility and unpredictability, instead for those who defend the concentration, control and limitation of spaces. The correlation between indicator and descriptor is close. As for the degree of physical effort, it is medium, while those of speed and strength are maximum. It is clear that in each of these game actions described in succession one must be able to manage the ball. All the individual fundamentals of the offenders are connected to this fabulous tool and based on the speed, direction, strength and position of the ball on the field, the individual and collective fundamentals of the defensive phase also develop (Di Domenico et al., 2019). The correlation between indicator and descriptor is tight, instead the degrees are all average, since the increase or decrease in the use of one of the three degrees mentioned above depends very much on the situation. A proposal of a technical nature could concern a session entirely dedicated to awareness and domination exercises, while from a tactical point of view it would be necessary to recreate as little situations as possible in the playing spaces. In this way not only to familiarize yourself with the ball, but also to adapt to the playing times and the ability to make decisions very quickly in confined spaces (Raiola, 2019).

\section{CONCLUSION}

Once the results of this study have been analysed, it is possible to observe the close correlation between rules, technique and tactics. So, the educational aspect, formed by respect for the rules, is the basis of football, without it the other two fundamental aspects could not be developed. Furthermore, it can be noted that the speed degree in most of the times has a maximum use, precisely because to be more effective than the opponent, one must be faster. as has been done for football, there will be other studies that will analyse the training and education of athletes as a primary source for learning the various techniques and tactics within other sports.

\section{REFERENCES}

Altavilla, G., Riela, L., Di Tore, A.P., Raiola, G. (2017). The physical effort required from professional football players in different playing positions. Journal of Physical Education and Sport, 17 (3), 200, pp. 2007-2012.

Altavilla, G., Furino, F., Marika, D.P., Raiola, G. (2015). Physical skills, sport learning and socioaffective education [Fizičke vještine, sportsko učenje I društveno-afektivno obrazovanje] Sport Science, 8, pp. 44-46.

Ceruso, R., Esposito, G., D'Elia, F. (2019) Analysis and evaluation of the qualitative aspects of the young players. Journal of Physical Education and Sport, 19, 266, pp. 1814-1819.

Ceruso, R., Esposito, G., Federici, A., Valentini, M., D'isanto, T. (2019) Preliminary work about the basis data for monitoring youth soccer team planning training, Journal of Human Sport and Exercise, 14 (Proc2), pp. S251-S257. https://doi.org/10.14198/ihse.2019.14.proc2.14

Ceruso, R., Esposito, G., D'elia, F. (2019). Coordination attached to the qualitative aspects of football, Journal of Physical Education and Sport, 19, 260, pp. 1773-1776.

Di Domenico, F., D'Isanto, T., Raiola, G. (2019). Role of speed and agility in the effectiveness of motor performance, Journal of Physical Education and Sport, 1. 271, pp. 1836-1842. 
Esposito, G., Ceruso, R., D'Elia, F. (2019). The importance of a technical-coordinative work with psychokinetic elements in the youth sectors of soccer academies, Journal of Physical Education and Sport, 19, 272, pp. 1843-1851.

Esposito, G., Ceruso, R., Valentini, M., D'Isanto, T. (2019). The use of enabling tests to provide a qualitative measurement of the sport skill level of small soccer players, Journal of Human Sport and Exercise, 14 (Proc4), pp. S592-S601. https://doi.org/10.14198/ihse.2019.14.proc4.17

Esposito, G., Ceruso, R., D'Isanto, T. (2019). Evaluation of some quantitative aspects in the young soccer players training process during puberty, Journal of Physical Education and Sport, 19, 261, pp. 1777 1783.

Gaetano, A. (2016). Relationship between physical inactivity and effects on individual health status, Journal of Physical Education and Sport, 16, pp. 1069-1074.

Gaetano, A., Gaetano, R. (2017). Physiological effects of warm-up and problems related to team sports, Sport Science, 10 (2), pp. 56-61.

Giordano, L., Federici, A., Valentini, M., D'Elia, F. (2019). Dribbling in football: Confronting learning theories, Journal of Human Sport and Exercise, 14 (Proc2), pp. S228-S232. https://doi.org/10.14198//hse.2019.14.proc2.10

Izzo, R., Varde'I, C.H., Raiola, G., Santinelli, F. (2019). Player performance model, comparison between youth professional (U-21) and professional first team football players: Different external load or not? Journal of Human Sport and Exercise, 14 (Proc4), pp. S991-S996. https://doi.org/10.14198/ihse.2019.14.proc4.61

Patrizia, T., Guido, F., Roberto, C., Rosaria, S., Salvatore, P., Raiola, G. (2019) The role of the educator/adult in supporting children of pre-school age in learning difficult tasks: The case of the playground "primo sport 0246" Journal of Physical Education and Sport, 19, 301, pp. 2015-2023.

Rago, V., Pizzuto, F., Raiola, G. (2017) Relationship between intermittent endurance capacity and match performance according to the playing position in sub-19 professional male football players: Preliminary results. Journal of Physical Education and Sport, 17 (2),103, pp. 688-691.

Russo, G., Nigro, F., Raiola, G., Ceciliani, A. (2019). Self-esteem in physically active middle school students, Journal of Physical Education and Sport, 19, 295, pp. 1984-1988.

Raiola, G. (2015). Sport skills and mental health. Journal of Human Sport and Exercise, 10(1proc), S369S376. https://doi.org/10.14198/jhse.2015.10.Proc1.27

Raiola, G. (2014). Motor control and learning skills according to cognitive and ecological dynamic approach in a vision on behaviorism, cognitive, Gestalt and phenomenology theories, Mediterranean Journal of Social Sciences, 5 (15), pp. 504-506. https://doi.org/10.5901/mjss.2014.v5n15p504

Raiola, G. (2019). Survey on exercise and sport sciences in Italy. Journal of Human Sport and Exercise, 14(4proc), S1163-S1168. https://doi.org/10.14198/jhse.2019.14.Proc4.81

Sgrò, F., Aiello, F., Casella, A., Lipoma, M. (2016) Offensive strategies in the European Football Championship 2012, Perceptual and Motor Skills, 123 (3), pp. 792-809. https://doi.org/10.1177/0031512516667455

Sgrò, F., Aiello, F., Casella, A., Lipoma, M. (2017). The effects of match-playing aspects and situational variables on achieving score-box possessions in euro 2012 football championship, Journal of Human Sport and Exercise, 12 (1), pp. 58-72. https://doi.org/10.14198//hse.2017.121.05

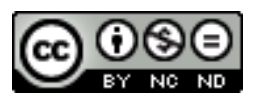

This work is licensed under a Attribution-NonCommercial-NoDerivatives 4.0 International (CC BY-NC-ND 4.0). 